\section{Immunological Characteristics of Denatured Proteins}

Afrer denaturation, some characteristic changes occur in the properties of proteins, among which are variations in immunological features. For example, the specific immunological behaviour of ovalbumin is altered and its antigenic capacity decreases considerably ${ }^{1-3}$. Although the specificity of denatured serum albumin does not change, its antigenic activity diminishes ${ }^{4}$ while both the specificity and activity of pseudoglobulin remain unchanged ${ }^{5}$.

Precipitin tests have been used in all these investigations, but the subject has not yet been investigated by immunodiffusion methods ${ }^{6}$. I have investigated the problem by double diffusion tests, and have been able to show the nature of the changed specificity and decreased antigenic activity of the denatured proteins depending on increases and decreases in the number of their determinant groups in a comparative and explicit way.

Three rabbits were injected with native and three with denatured ovalbumin, bovine serum albumin and bovine pseudoglobulin (prepared by ammonium sulphate precipitation $)^{7}$ respectively. The proteins were denatured without coagulation by maintaining the protein solutions in a water bath at $100^{\circ} \mathrm{C}$ for $1 \mathrm{~h}$ at $p \mathrm{H} 10$, and then neutralizing them ${ }^{8}$. The reactions of antisera with antigens were examined by the Ouchterlony $\operatorname{method}^{\ominus}$, and the pictures of precipitin lines taken on the third and eighth days.

Antisera to denatured protein produced a weak precipitin line with denatured ovalbumin or serum albumin (after 5 days) but no line was observed in the case of pseudoglobulin. The same antisera with their corresponding native protein antigens produced one line in the case of ovalbumin, two in that of serum albumin and three lines for pseudoglobulin (Fig. 1). Thus the reactions of denatured protein antisera with native antigens are more intense than the reactions of the same antisera with denatured antigens.

Antisera to native protein produced with their homologous native antigens two strong lines for ovalbumin, one strong line for serum albumin, and three strong lines for pseudoglobulin. The same antisera produced no line with the corresponding denatured protein antigens of all three types (Fig. 1).

These findings indicate that proteins denatured by heating at $p H \mathbf{H}$ can produce strong antibodies, although their ability to bind and precipitate these antibodies is reduced. It appears that the changes in specific immunological behaviour of denatured proteins cannot be generally described. Various proteins exhibit a serological change which depends on their constitutions.

Antigenic specificity is caused not by one single determinant group, but is influenced by polar groups adjacent to this determinant group ${ }^{10}$. Denaturation of the protein involves changes in the original distances between these groups and the disappearance of the relations responsible for the characteristics of the determinant groups, which cause the observed variations in specificity.

Even if the secondary structure of the native protein changes by denaturation, however, a number of the determinant groups may remain active and serve as a template ${ }^{11}$ for their own complementary antibodies in the reticulo-endothelial system.

F. Arat

Department of Biochemistry,

University of Istanbul, Turkey.

${ }^{1}$ Wu. Hsien, Tenbroeck, C., and Li, C. P., Ber. Physiol., 48, 299 (1928).

2 MacPherson, C. F. C., and Heidelberger, M., J. Amer. Chem. Soc., 6\%, 585 (1945).

${ }^{3}$ Haurowitz, F., and Bursa, F., Rev. Fac. Sc. Univ. Istanbut, B, 10, 283 (1945).

4 Erickson, J. O., and Neurath, H., J. Exp. Med., 78, 1 (1943).

6 Erickson, J. O., and Neurath, H., J. Gen. Physiol., 28, 421 (1945).

- Crowle, A. J., Immunodiffusion (Academic Press, New York, 1961).

' Grabar, P., Techniques de laboratoire (Masson, Paris, 1963).

- Haurowitz, F., and Tekman, S., Biochim. Biophys. Acta, 1, 484 (1047).

- Ouchteriony, O., Acta Path. Microbiol. Scand., 26, 507 (1949).

${ }^{10}$ Heidelberger, M., Ann. Rev. Biochem., 25, 641 (1956).

"Haurowitz, F., Ann. Rev. Biochem., 29, 609 (1960).

\section{PHARMACOLOGY}

\section{Action of Chlorpromazine on Non-specific Phosphatase bound to Membranes in Brain Tissue of the Rat}

THE mechanism of action of psychotropic drugs has been widely investigated. For a number of years, work has been focused on this problem in our laboratory. We have investigated particularly the amino-acids ${ }^{1-3}$ and phosphatases $^{4,5}$ of the brain. We found that phosphatase activity in brain, measured in the physiological range of $p H(7 \cdot 2-7 \cdot 5)$ with $p$-nitrophenolphosphate as a substratc. was markedly increased by chlorpromazine in vitro (Table 1) as well as in vivo (Table 2).

Table 1 shows that this effect did not occur to the same extent in similar experiments with liver and kidney tissue. Table 1 also shows that the detergent 'Sterox' causes an increase in phosphatase activity. This finding led us to examine the nature of the increase of phosphatase activity. Whether the increase resulted from solubilization of protein by the drugs (chlorpromazine slightly diminishes the surface tension of the water-air interface ${ }^{6}$ ), from enzyme kinetic or from other mechanisms, was partly elucidated. We pre-incubated rat brain homogenates with various drugs or detergents and then centrifuged at $105,000 \mathrm{~g}$. The phosphatase activity of the supernatant did not change in the series treated with drugs, but in the detergent series the supernatant activity was almost doubled. This indicates that the similar results shown in

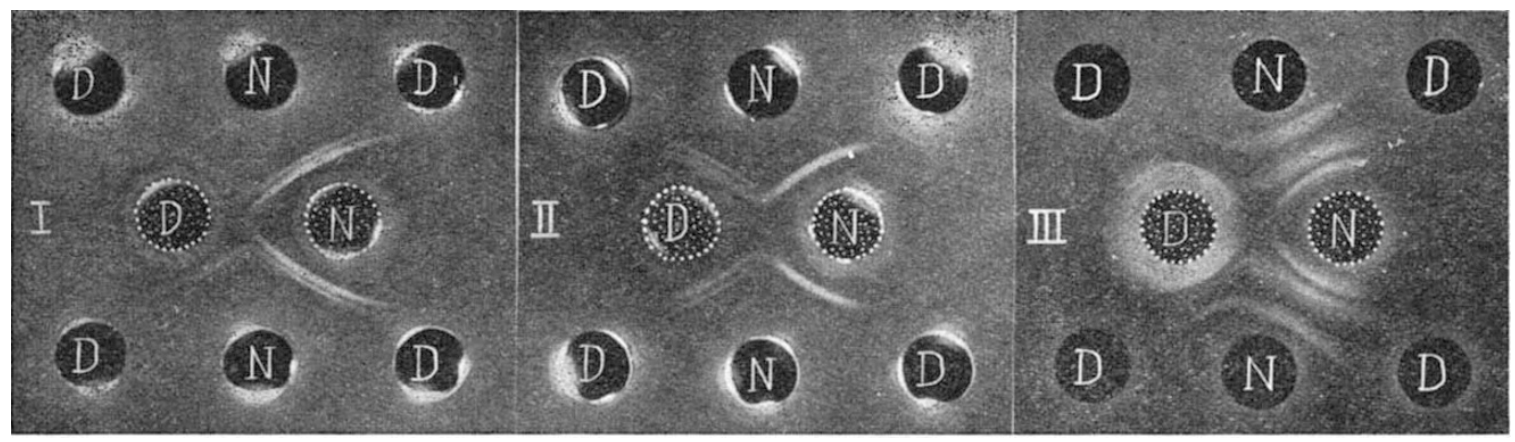

Fig. 1. Double diffusion tests in agar. Pictures taken on the third day. I, Ovalbumin; II, serum albumin; III, pseudoglobulin. Clear circles indicate antigens. Dotted circles indicate antisera. $N$, Natjve; $D$, denatured. Antigens $100 \mathrm{mg} / 100 \mathrm{ml}$. 